\title{
CORRECTION
}

\section{Correction to: Suspended Again: The Racialized Consequences of a 9th Grade Suspension on Future Suspension Patterns}

\author{
Benjamin W. Fisher ${ }^{1,2} \cdot$ Stephanie A. Wiley ${ }^{3} \cdot$ Anne McGlynn-Wright $^{4}$
}

Published online: 15 June 2021

๑) Springer Science+Business Media, LLC, part of Springer Nature 2021

\section{Correction to: Race Soc Probl.}

https://doi.org/10.1007/s12552-021-09332-5

The original version of this article unfortunately contained an error. The authors Dr. Stephanie A. Wiley and Dr. Anne McGlynn-Wright affiliations are corrected with this erratum.

The original article has been corrected.

Publisher's Note Springer Nature remains neutral with regard to jurisdictional claims in published maps and institutional affiliations.

The original article can be found online at https://doi.org/10.1007/ s12552-021-09332-5.

Benjamin W. Fisher

bwfisher@fsu.edu

1 College of Criminology \& Criminal Justice, Florida State,

University, Tallahassee, FL, USA

2 Department of Criminal Justice, University of Louisville, Louisville, KY, USA

3 Simon Fraser University, Burnaby, Canada

4 Newcomb Institute, Tulane University, New Orleans, LA, USA 